\title{
DISSIMILARIDADE GENÉTICA ENTRE GENÓTIPOS DE AVEIA
}

\author{
VOLMIR SERGIO MARCHIORO ${ }^{1}$ \\ FERNANDO IRAJÁ FÉLIX DE CARVALHO ${ }^{2}$ \\ ANTONIO COSTA DE OLIVEIRA ${ }^{2}$ \\ PEDRO JACINTO CRUZ ${ }^{3}$ \\ CLAUDIR LORENCETTI ${ }^{3}$ \\ GIOVANI BENIN ${ }^{3}$ \\ JOSÉ ANTÔNIO GONZALES DA SILVA ${ }^{3}$ \\ DOUGLAS A. M. SCHMIDT ${ }^{4}$
}

\begin{abstract}
RESUMO - Dezoito genótipos de aveia foram testados quanto à dissimilaridade genética, com e sem o controle de moléstias da parte aérea. As variáveis avaliadas foram rendimento de grãos desaristados, peso de mil grãos, peso do hectolitro, estatura de planta e dias da emergência à floração. Foram empregados análises por variáveis canônicas e técnicas de agrupamento por meio dos métodos de otimização de Tocher e o método hierárquico do vizinho mais próximo, tendo como medida de dissimilaridade a distância generalizada de Mahalanobis. Pelos resultados, constatou-se
\end{abstract}

significativa dissimilaridade genética entre os genótipos, indicando a existência de variabilidade para os caracteres avaliados. O método de Tocher e o método do vizinho mais próximo permitiram a separação dos genótipos em grupos distintos, possibilitando a identificação de futuros genitores que possam ser utilizados em cruzamentos artificiais que produzam progênies com maior heterose. Os caracteres que mais contribuíram para a dissimilaridade genética foram o peso do hectolitro e a estatura de planta.

TERMOS PARA INDEXAÇÃO: Ambiente, técnicas multivariadas, métodos de agrupamento.

\section{GENETIC DISSIMILARITY AMONG OAT GENOTYPES}

\begin{abstract}
Eighteen oat genotypes were tested for genetic dissimilarity, with and without shoot disease control. The evaluated variables were grain yield, weight of one thousand grains, test weight, plant stature and days from emergence to flowering. Cannonical variables and clustering methods by Tocher's optimization test and the hierarchical method of nearest neighbor were employed, having as a measure of dissimilarity the general distance of Mahalanobis. The
\end{abstract}

results showed a significant genetic dissimilarity among the genotypes, indicating the presence of genetic variability for the evaluated traits. Tocher's and nearest neighbor methods allowed the separation of genotypes in distinct groups, enabling the identification of potential parents for artificial crosses to obtain progenies with higher heterosis. The major traits contributing to genetic dissimilarity in our study were test weight and plant stature.

INDEX TERMS: Environment, multivariate techniques, cluster methods.

\section{INTRODUÇÃO}

O conhecimento de diferenças em constituições genéticas dentro de grupos ou entre grupos de genótipos tem sido de grande importância para qualquer programa de melhoramento. Importância que está relacionada com a necessidade de identificar genitores com diferenças genéticas que produzam progênies de maior heterose, aumentando, assim, a probabilidade na obtenção de indivíduos superiores (Cruz \& Regazzi, 1997).

1. Engenheiro Agrônomo, estudante do Curso de Doutorado em Agronomia (Fitomelhoramento) da Universidade Federal de Pelotas (UFPel). Pelotas/RS - Bolsista da Capes. volmirsm@ufpel.tche.br - vmarchioro@bol.com.br

2. Engenheiro Agrônomo (Ph.D.), Professor do Departamento de Fitotecnia da Faculdade de Agronomia Eliseu Maciel (FAEM/UFPel) - Campus Universitário, Caixa Postal 354 - 96001-970, Pelotas/RS. caravalho@ufpel.tche.br.

3. Engenheiro Agrônomo, estudante do Curso de Pós-Graduação em Agronomia (Fitomelhoramento) da UFPel.

4. Estudante do Curso de Agronomia da UFPel - Bolsista da FAPERGS. 
Medidas de dissimilaridade genética, como forma de caracterizar e identificar constituições genéticas distintas de diferentes espécies, determinadas pelo isolamento reprodutivo, têm despertado o interesse de vários autores (Santos et al., 1997; Gaur et al., 1978; Casler, 1995). Entre as medidas de dissimilaridade que podem evidenciar a intensidade de variabilidade genética, a distância Euclediana e a distância de Mahalanobis são as mais utilizadas por melhoristas em programas de melhoramento genético de plantas. De acordo com Gaur et al. (1978), a análise multivariada pode ser empregada como uma poderosa ferramenta para estimar a dissimilaridade genética, com o intuito de auxiliar na escolha de constituições genéticas que poderão resultar, por meio de suas progênies, em recombinações superiores. Essa técnica, segundo Machado (1999), é a mais eficiente e utilizada na identificação de dissimilaridade genética.

Outra técnica importante no estudo de dissimilaridade genética é a análise de agrupamento que, segundo Cruz \& Regazzi (1997), tem por finalidade reunir e classificar os genótipos em vários grupos, de tal forma que exista homogeneidade dentro e heterogeneidade entre grupos formados. Os métodos de agrupamento mais utilizados em programas de melhoramento genéticos de plantas têm sido os hierárquicos e os de otimização. Nos métodos hierárquicos, os genitores são agrupados por um processo que se repete em vários níveis, até que seja estabelecido um dendrograma, e nos de otimização, é realizada a partição do conjunto de genitores em subgrupos mutuamente exclusivos por meio da maximização ou minimização de uma medida preestabelecida (Cruz \& Regazzi, 1997).

O Ensaio Brasileiro de Cultivares Recomendadas de Aveia tem sido conduzido desde 1996 na Universidade Federal de Pelotas (UFPel), e freqüentemente os genótipos testados são utilizados em cruzamentos artificiais para estudos específicos, dentro do programa de melhoramento genético da espécie; nesse sentido, com o presente trabalho tevese por objetivo principal caracterizar morfologicamente a dissimilaridade genética e promover o agrupamento dos genótipos em estudo.

\section{MATERIAL E MÉTODOS}

Os genótipos inseridos na Tabela 1, com suas respectivas genealogias, foram avaliados no Ensaio Brasileiro de Cultivares Recomendadas de Aveia no Centro Agropecuário da Palma (CAP/UFPel), no ano agrícola de 2000. A adubação de base e de cobertura foi feita de acordo com a analise de solo. O controle de moléstias da parte aérea foi realizado com a utilização de fungicida FOLICUR CE, na dose de 0,75 1.ha ${ }^{-1}$, em duas aplicações. $\mathrm{O}$ delineamento empregado foi o de blocos casualizados com seis repetições, sendo três com e três sem a aplicação de fungicida para o controle de moléstias da parte aérea. As parcelas experimentais constaram de cinco linhas espaçadas entre si em 0,2 m, com $5 \mathrm{~m}$ de comprimento e uma densidade de semeadura de aproximadamente 300 sementes aptas por $\mathrm{m}^{2}$. As variáveis avaliadas no experimento foram: rendimento de grãos desaristados (RGD), peso de mil grãos (PMG), peso do hectolitro $(\mathrm{PH})$, estatura de planta $(E P)$ e dias da emergência à floração (DEF). Os dados de rendimento de grãos desaristados em kg.ha ${ }^{-1}$ foram obtidos na colheita das três linhas centrais de cada parcela; os do peso de mil grãos em gramas, por meio da contagem e posterior pesagem de mil grãos de cada parcela; os do peso do hectolitro em kg.hl ${ }^{-1}$, pela pesagem de um volume conhecido de grãos de cada parcela; os de estatura de planta em $\mathrm{cm}$, pela média de três medidas em cada parcela, obtidas aproximadamente 21 dias após a antese, computada pelo comprimento do colmo, em $\mathrm{cm}$, da superfície do solo até o ápice da inflorescência, excluindo as aristas e os de dias da emergência à floração (dias), pela diferença do dia da emergência até o dia em que $50 \%$ das plantas existentes na parcela apresentassem a inflorescência do afilho principal, excluindo a folha-bandeira.

A análise de comparação de médias foi realizada utilizando o teste descrito por Scott \& Knott (1974); o emprego desse teste possibilita a definição dos subconjuntos de genótipos que diferem significativamente entre si.

As medidas de dissimilaridade foram determinadas segundo o modelo de análise multivariada, o que permitiu a obtenção da matriz de dissimilaridade, da matriz de covariância residual e das médias dos genótipos. Posteriormente, foram determinadas as variáveis canônicas, conforme relatado por Rao (1952). As variáveis canônicas, quando utilizadas em estudos de dissimilaridade genética, têm como propósito a identificação de genótipos similares em gráficos de dispersão bi ou tridimensionais. Para esse tipo de estudo, as primeiras variáveis canônicas devem envolver, no mínimo, aproximadamente $80 \%$ da variação total dos genótipos, em que cada variável é uma combinação linear das variáveis originais analisadas. 
TABELA 1 - Genealogia dos genótipos utilizados na análise.

\begin{tabular}{|c|c|}
\hline Genótipo & Genealogia \\
\hline UPF 7 & TCFP / X2503-1 \\
\hline UPF 15 & QR 306 = Coker 82-33 // IL3376 / OA338 \\
\hline UPF 16 & Coronado / X1799-2/Sel 11 Passo Fundo // X3530-40 \\
\hline UPF 17 & Coronado / X1799-2/Sel 11 Passo Fundo // X3530-40 \\
\hline UPF 18 & UPF $85 S 0238$ x UPF 12 \\
\hline UPF 19 & 90 AS-30 (UPF 16) / 90 AS-28 (Cor2/Ctz3/Pendek/ME 1563 \\
\hline UFRGS 7 & X1205 / FLA 1086 \\
\hline UFRGS 14 & $895165 / / \mathrm{Cor}^{2} / \mathrm{Ctz}^{3} /$ Pendek / ME 1563 \\
\hline UFRGS 15 & $\mathrm{Cor}^{2} / \mathrm{Ctz}^{3} / \mathrm{Pendek} / \mathrm{ME}$ 1563/C16 CRcpx/C7512/SRcpx/74 C8014 \\
\hline UFRGS 16 & C16 CRCPS / C7512 / SR CPX / 74 C8014 \\
\hline UFRGS 17 & $\mathrm{Cor}^{2} / \mathrm{Ctz}^{3}$ / Pendek / ME 1563 // 76-29 / 76-23 / 75-28 / CI833 \\
\hline UFRGS 18 & Cocker 81C42 // Cor $^{2} / \mathrm{Ctz}^{3} /$ Pendek / ME 1563 \\
\hline UFRGS 19 & UFRGS 884110 / UFRGS 884021-1 \\
\hline URS 20 & UFRGS 86A1194-2 / UFRGS 8 \\
\hline URS 21 & UFRGS 10 / CTC 84B993 \\
\hline IAC 7 & V 155, ML-II-CV-77-CV78-R78-79CV-79-CV80 (Mëxico) \\
\hline OR 2 & Desconhecida \\
\hline OR 3 & UFRGS 871547 // UFRGS 8 / ORI-892 \\
\hline
\end{tabular}

O grau de dissimilaridade genética entre os genótipos foi estimado usando estatística de Mahalanobis $\left(\mathrm{D}^{2}\right)$ a partir das médias dos genótipos e da matriz de covariância residual. Para o agrupamento dos genótipos, foi empregado o método hierárquico do vizinho mais próximo na formação dos dendrogramas, que consiste em identificar na matriz de dissimilaridade os genótipos mais similares, formando um grupo inicial e, a partir desse grupo, estimar as distâncias em relação aos demais genótipos. Utilizando a metodologia proposta por Mourão Junior (2001), através de valores tabelados da distribuição empírica de Mahalanobis $\left(\mathrm{D}^{2}\right)$, em função do número de genótipos e do número de variáveis, foi efetuado o corte nos dendrogramas a $95 \%$ de probabilidade. $\mathrm{O}$ agrupamento foi realizado também por meio do método de otimização de Tocher, o qual consiste em identificar na matriz de dissimilaridade o par de genótipos mais similares, formando o grupo inicial e, a partir desse, é avaliada a possibilidade de inclusão de novos genótipos no grupo, adotando o critério de que a média das medidas de dissimilaridade dentro de cada grupo deve ser menor que as distâncias médias entre quaisquer grupos (Cruz \& Regazzi, 1997).
A importância relativa dos caracteres avaliados quanto à dissimilaridade genética observada entre os genótipos foi feita pela análise dos coeficientes das transformações lineares para a obtenção das variáveis canônicas, conforme Cruz (1990), e por meio da partição dos componentes $\mathrm{D}^{2}$, relativos a cada caráter, no total da dissimilaridade genética observada, de acordo com a recomendação de Singh (1981).

Todas as análises foram realizadas separadamente para cada ambiente utilizando o programa computacional Genes desenvolvido por (Cruz, 2001).

\section{RESULTADOS E DISCUSSÃO}

Pelos resultados, constatou-se significativa dissimilaridade genética entre os genótipos avaliados. Na Tabela 2 estão inseridas as médias dos caracteres comparadas pelo teste de Scott \& Knott (1974) para cada genótipo. As médias mostraram diferenças significativas entre si em todos os caracteres avaliados, tanto com ou sem a aplicação de fungicida; entretanto, um maior número de diferenças significativas foi observado para o caráter dias da emergência à floração 
(DEF), com a aplicação de fungicida, que evidenciou cinco classes distintas: "a", "b", "c", "d" e "e", e para os caracteres dias da emergência à floração (DEF) e estatura de planta (EP), sem aplicação de fungicida, quatro classes distintas foram observadas: "a", "b", "c" e "d". No caráter ciclo vegetativo (DEF), o número de classes foi menor na ausência de fungicida, devido ao prolongamento do ciclo de alguns genótipos com a aplicação de fungicida, como foi o caso da UPF 7, UPF 18, UFRGS 15 e UFRGS 16, permitindo com isso que os genótipos UPF 7, UPF 18 e UFRGS 15 que se agrupavam na classe "a", sem fungicida, permitissem a junção com os genótipos UFRGS 16 e UFRGS 18, na mesma classe "a", em ausência da aplicação de fungicida para o controle de moléstias da parte aérea.
Por outro lado, os demais caracteres, exceto rendimento de grãos desaristados (RGD), tiveram um maior número de classes sem a aplicação de fungicida, devido à drástica redução na expressão dos caracteres para alguns genótipos, como a UFRGS 7 e UFRGS 15 para o peso de mil grãos (PMG), UFRGS 15 e UFRGS 18 para o caráter peso do hectolitro (PH) e UPF 16 e UFRGS 7 para o caráter estatura de planta (EP). Pela genealogia desses genótipos, incluída na Tabela 1, fica evidente que a formação de classes não foi de responsabilidade exclusiva das constituições genéticas, mas também pelo efeito do ambiente.

TABELA 2 - Médias dos caracteres avaliados nos 18 genótipos: rendimento de grãos Desaristados (RGD), peso de mil grãos (PMG), peso do hectolitro $(\mathrm{PH})$, estatura de planta $(\mathrm{EP})$ e dias da emergência à floração (DEF).

\begin{tabular}{|c|c|c|c|c|c|c|c|c|c|c|}
\hline \multirow[b]{2}{*}{ Genótipo } & \multicolumn{5}{|c|}{ Com fungicida } & \multicolumn{5}{|c|}{ Sem fungicida } \\
\hline & $\begin{array}{c}\text { RGD } \\
\left({\left.\mathrm{kg} . h a^{-1}\right)}^{-1}\right.\end{array}$ & $\begin{array}{c}\text { PMG } \\
\text { (g) }\end{array}$ & $\begin{array}{c}\text { PH } \\
\left({\left.\mathrm{kg} . h l^{-1}\right)}^{-1}\right.\end{array}$ & $\begin{array}{c}\text { EP } \\
(\mathrm{cm})\end{array}$ & $\begin{array}{c}\text { DEF } \\
(\text { dias })\end{array}$ & $\begin{array}{c}\text { RGD } \\
\left(\text { kg.ha }^{-1}\right)\end{array}$ & $\begin{array}{c}\text { PMG } \\
\text { (g) }\end{array}$ & 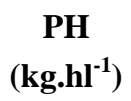 & $\begin{array}{c}\text { EP } \\
(\mathrm{cm})\end{array}$ & $\begin{array}{c}\text { DEF } \\
\text { (dias) }\end{array}$ \\
\hline UPF 7 & $3116 b$ & $28 \mathrm{~b}$ & $48 \mathrm{~b}$ & $117 \mathrm{a}$ & $112 \mathrm{a}$ & $2242 \mathrm{a}$ & $25 \mathrm{~b}$ & $40 \mathrm{c}$ & $116 \mathrm{~b}$ & $104 \mathrm{a}$ \\
\hline UPF 15 & $3462 \mathrm{~b}$ & $33 a$ & $46 \mathrm{~b}$ & $121 \mathrm{a}$ & $103 \mathrm{c}$ & $2182 \mathrm{a}$ & $26 \mathrm{~b}$ & $38 \mathrm{c}$ & $115 \mathrm{~b}$ & $100 \mathrm{~b}$ \\
\hline UPF 16 & $4015 \mathrm{a}$ & $31 \mathrm{a}$ & $49 \mathrm{~b}$ & $106 \mathrm{~b}$ & $100 \mathrm{c}$ & $1280 \mathrm{~b}$ & $25 \mathrm{~b}$ & $32 \mathrm{c}$ & $95 \mathrm{~d}$ & $97 \mathrm{c}$ \\
\hline UPF 17 & $2758 \mathrm{~b}$ & $37 \mathrm{a}$ & $48 \mathrm{~b}$ & $99 \mathrm{~b}$ & $99 \mathrm{c}$ & $1280 \mathrm{~b}$ & $25 \mathrm{~b}$ & $32 \mathrm{c}$ & $95 \mathrm{~d}$ & $96 \mathrm{c}$ \\
\hline UPF 18 & $3244 \mathrm{~b}$ & 35 a & $51 \mathrm{a}$ & $133 \mathrm{a}$ & $110 \mathrm{a}$ & $1762 \mathrm{~b}$ & $25 \mathrm{~b}$ & $40 \mathrm{c}$ & $127 \mathrm{a}$ & $102 \mathrm{a}$ \\
\hline UPF 19 & $3238 \mathrm{~b}$ & $31 \mathrm{a}$ & $50 \mathrm{a}$ & $124 \mathrm{a}$ & $101 \mathrm{c}$ & $2378 \mathrm{a}$ & $29 \mathrm{a}$ & $43 \mathrm{~b}$ & $121 \mathrm{a}$ & $98 \mathrm{c}$ \\
\hline UFRGS 7 & $3334 \mathrm{~b}$ & $27 \mathrm{~b}$ & $53 \mathrm{a}$ & $111 \mathrm{~b}$ & 99 c & $2402 \mathrm{a}$ & $19 \mathrm{c}$ & $39 \mathrm{c}$ & $103 \mathrm{c}$ & $95 \mathrm{c}$ \\
\hline UFRGS 14 & $3945 \mathrm{a}$ & $37 \mathrm{a}$ & $49 \mathrm{~b}$ & $106 \mathrm{~b}$ & $102 \mathrm{c}$ & $2667 \mathrm{a}$ & $31 \mathrm{a}$ & $38 \mathrm{c}$ & $107 \mathrm{c}$ & $99 \mathrm{~b}$ \\
\hline UFRGS 15 & $3875 \mathrm{a}$ & 33 a & $44 \mathrm{~b}$ & $100 \mathrm{~b}$ & $109 \mathrm{a}$ & $1449 b$ & $19 \mathrm{c}$ & $30 \mathrm{c}$ & $99 \mathrm{~d}$ & $101 \mathrm{a}$ \\
\hline UFRGS 16 & $3114 \mathrm{~b}$ & $29 \mathrm{~b}$ & $46 \mathrm{~b}$ & $115 \mathrm{a}$ & $108 \mathrm{~b}$ & $1891 \mathrm{~b}$ & $25 \mathrm{~b}$ & $41 \mathrm{~b}$ & $115 \mathrm{~b}$ & $101 \mathrm{a}$ \\
\hline UFRGS 17 & $3456 \mathrm{~b}$ & $33 \mathrm{a}$ & $52 \mathrm{a}$ & $122 \mathrm{a}$ & $102 \mathrm{c}$ & $1993 \mathrm{~b}$ & $25 \mathrm{~b}$ & $41 \mathrm{~b}$ & $122 \mathrm{a}$ & $100 \mathrm{~b}$ \\
\hline UFRGS 18 & $3647 \mathrm{a}$ & $28 \mathrm{~b}$ & $45 \mathrm{~b}$ & $103 \mathrm{~b}$ & $107 \mathrm{~b}$ & $1115 \mathrm{~b}$ & $20 \mathrm{c}$ & $31 \mathrm{c}$ & $98 \mathrm{~d}$ & $105 \mathrm{a}$ \\
\hline UFRGS 19 & $3334 \mathrm{~b}$ & $29 \mathrm{~b}$ & $55 \mathrm{a}$ & $104 \mathrm{~b}$ & $97 d$ & 2398 a & $22 \mathrm{c}$ & $45 \mathrm{a}$ & $99 \mathrm{~d}$ & $92 \mathrm{~d}$ \\
\hline URS 20 & $3218 \mathrm{~b}$ & $31 \mathrm{a}$ & $54 \mathrm{a}$ & $111 \mathrm{~b}$ & $100 \mathrm{c}$ & 2589 a & $27 \mathrm{~b}$ & $49 a$ & $106 \mathrm{c}$ & $97 \mathrm{c}$ \\
\hline URS 21 & $3369 \mathrm{~b}$ & $32 \mathrm{a}$ & $53 \mathrm{a}$ & $117 \mathrm{a}$ & $97 \mathrm{~d}$ & 3364 a & $28 \mathrm{a}$ & $50 \mathrm{a}$ & $114 \mathrm{~b}$ & $93 \mathrm{~d}$ \\
\hline IAC 7 & $2702 \mathrm{~b}$ & $32 \mathrm{a}$ & $53 \mathrm{a}$ & $101 \mathrm{~b}$ & $93 \mathrm{e}$ & $1631 \mathrm{~b}$ & $27 \mathrm{~b}$ & $42 \mathrm{~b}$ & $101 \mathrm{~d}$ & $91 \mathrm{~d}$ \\
\hline OR 2 & $3782 \mathrm{a}$ & $26 \mathrm{~b}$ & $45 \mathrm{~b}$ & $109 \mathrm{~b}$ & $100 \mathrm{c}$ & 2569 a & $21 \mathrm{c}$ & $47 \mathrm{a}$ & $107 \mathrm{c}$ & $97 \mathrm{c}$ \\
\hline OR 3 & $4569 \mathrm{a}$ & $38 \mathrm{a}$ & $51 \mathrm{a}$ & $118 \mathrm{a}$ & $101 \mathrm{c}$ & $2522 \mathrm{a}$ & $32 \mathrm{a}$ & $44 \mathrm{~b}$ & $113 \mathrm{~b}$ & $98 \mathrm{c}$ \\
\hline Média & 3435,4 & 31,7 & 49,5 & 112,1 & 102,2 & 2095,2 & 25,0 & 40,1 & 108,5 & 98,1 \\
\hline $\mathrm{CV}(\%)$ & 14,8 & 10,9 & 4,8 & 5,6 & 1,7 & 19,9 & 8,1 & 5,8 & 3,9 & 2,1 \\
\hline
\end{tabular}

*Médias seguidas de letras distintas na coluna diferem significativamente, a $5 \%$ de probabilidade, pelo teste de Scott-Knott. 
Nas avaliações das variáveis canônicas, os escores das três primeiras variáveis, relativas a cada genótipo e incluídos na Tabela 3, mostram que as duas primeiras variáveis canônicas explicam cerca de $82,19 \%$ da variação total $(66,30 \%$ relativo à primeira e $15,89 \%$ relativo à segunda variável canônica), com a aplicação de fungicida. Sem a aplicação de fungicida, as duas primeiras variáveis canônicas explicam cerca de $77,59 \%$ da variação total $(44,43 \%$ relativo à primeira e $33,16 \%$ relativo à segunda variável canônica).

Com esses resultados foi possível a visualização gráfica bidimensional dos genótipos analisados, utilizando a primeira e a segunda variáveis canônicas, como mostram as Figuras 1 e 2, com e sem o controle de moléstias da parte aérea, respectivamente. $\mathrm{Na}$ comparação entre os dois gráficos de dispersão, com e sem a utilização de fungicida, pode ser observado que os genótipos não se agruparam de igual maneira, permitindo estabelecer a hipótese de que o ambiente participou significativamente na expressão fenotípica das constituições genéticas avaliadas. Na Figura 1, com fungicida, verifica-se que os genótipos permaneceram mais próximos uns dos outros, em relação à Figura 2, sem fungicida, em que ocorreu maior dispersão. Essa variação na dispersão gráfica tem por base o fato de a variável canônica 1 , com fungicida, explicar $66,30 \%$ da variação genética total, em relação à variável canônica 1 , sem fungicida, que expressa apenas $44,43 \%$ da variação genética total.

TABELA 3 - Escores dos genótipos em relação às três primeiras variáveis canônicas obtidas na avaliação de dissimilaridade genética.

\begin{tabular}{|c|c|c|c|c|c|c|}
\hline \multirow{3}{*}{ Genótipo } & \multicolumn{6}{|c|}{ Variáveis canônicas } \\
\hline & \multicolumn{3}{|c|}{ Com fungicida } & \multicolumn{3}{|c|}{ Sem fungicida } \\
\hline & $\mathbf{1}^{\mathbf{0}}$ & $2^{-}$ & $3^{-}$ & $\mathbf{1}^{\mathbf{0}}$ & $2^{-9}$ & $3^{-}$ \\
\hline UPF 7 & 55,29 & 21,36 & 23,50 & 44,89 & 44,70 & $-12,96$ \\
\hline UPF 15 & 51,20 & 22,49 & 23,02 & 43,38 & 42,92 & $-10,93$ \\
\hline UPF 16 & 48,97 & 20,93 & 23,93 & 36,84 & 40,98 & $-9,61$ \\
\hline UPF 17 & 48,04 & 20,14 & 25,38 & 36,84 & 40,98 & $-9,61$ \\
\hline UPF 18 & 54,42 & 24,62 & 24,44 & 46,17 & 45,26 & $-11,45$ \\
\hline UPF 19 & 49,98 & 23,36 & 22,91 & 45,64 & 42,39 & 9,49 \\
\hline UFRGS 7 & 47,60 & 21,60 & 22,91 & 41,70 & 38,32 & $-14,02$ \\
\hline UFRGS 14 & 50,18 & 21,40 & 25,86 & 41,82 & 43,22 & $-9,04$ \\
\hline UFRGS 15 & 53,67 & 19,32 & 24,99 & 38,30 & 43,70 & $-14,06$ \\
\hline UFRGS 16 & 52,24 & 21,15 & 22,61 & 44,58 & 43,09 & $-11,99$ \\
\hline UFRGS 17 & 50,04 & 23,52 & 23,87 & 45,46 & 42,84 & $-11,01$ \\
\hline UFRGS 18 & 52,64 & 19,52 & 23,62 & 38,47 & 43,35 & $-13,60$ \\
\hline UFRGS 19 & 45,55 & 21,27 & 23,68 & 42,28 & 36,18 & $-12,73$ \\
\hline URS 20 & 47,91 & 22,20 & 24,18 & 45,15 & 38,52 & $-11,35$ \\
\hline URS 21 & 47,05 & 23,07 & 23,38 & 46,71 & 37,70 & $-10,53$ \\
\hline IAC 7 & 43,76 & 20,93 & 23,76 & 40,60 & 37,30 & $-8,66$ \\
\hline OR 2 & 50,91 & 20,22 & 21,97 & 45,10 & 37,84 & $-14,21$ \\
\hline OR 3 & 49,64 & 23,11 & 25,11 & 44,17 & 41,37 & $-7,75$ \\
\hline Variância & 9,29 & 2,23 & 1,04 & 10,55 & 7,88 & 4,03 \\
\hline Variância (\%) & 66,30 & 15,89 & 7,42 & 44,43 & 33,16 & 16,95 \\
\hline Variância acum. (\%) & 66,30 & 82,19 & 89,60 & 44,43 & 77,59 & 97,93 \\
\hline
\end{tabular}




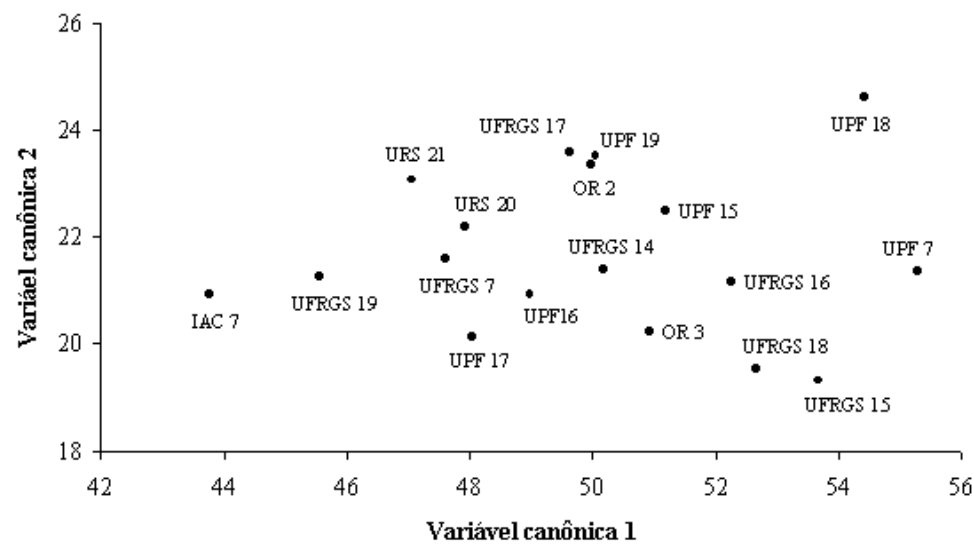

FIGURA 1 - Dispersão de escores dos dezoito genótipos em relação às duas primeiras variáveis canônicas, com fungicida.

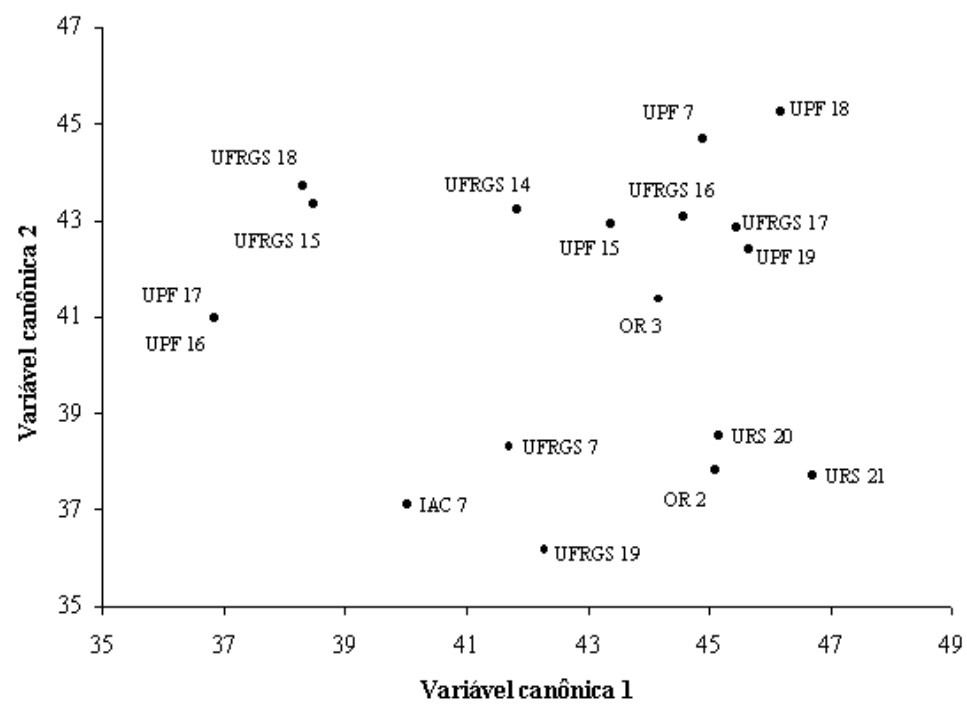

FIGURA 2 - Dispersão de escores dos dezoito genótipos em relação às duas primeiras variáveis canônicas, sem fungicida.

Certamente essa diferença entre as variáveis canônicas foi devida ao efeito de ambiente, em que os caracteres que mais contribuíram para a dissimilaridade genética total entre os genótipos, como é o caso da estatura de planta (EP) e do peso do hectolitro (PH) (Tabela 7), foram menos variáveis entre os genótipos quando foi aplicado fungicida, em relação à ausência de fungicida, como revela a Tabela 2. A dispersão gráfica também permitiu a separação dos genótipos em grupos, podendo ser utilizada como uma estratégia para selecionar genótipos divergentes a serem utilizados em cruzamentos artificiais, como é o caso dos genótipos 
IAC 7 e UPF 7 com aplicação de fungicida (Figura 1) e dos genótipos UPF 16 e URS 21 sem aplicação de fungicida (Figura 2).

Quando foi efetuado o agrupamento dos genótipos através da distância generalizada de Mahalanobis $\left(\mathrm{D}^{2}\right)$ e o método de otimização de Tocher (Tabela 4), sete grupos distintos foram detectados. Comparando a formação desses grupos com a genealogia dos genótipos analisados (Tabela 1), pode ser observado que a aplicação de fungicida para o controle de moléstias da parte aérea influenciou de maneira diferenciada na expressão fenotípica de genótipos com a mesma genealogia ou com genealogia extremamente similar, como é o caso dos genótipos UPF 16 e UPF 17, que ficaram no mesmo grupo quando não foi empregado fungicida, e em presença de fungicida, esses genótipos participaram de grupos distintos. O mesmo ocorreu com os genótipos UFRGS 15 e UFRGS 18, que são bastante similares em relação à genealogia.

Utilizando o método hierárquico do vizinho mais próximo na formação de dendrogramas (Figuras 3 e 4), novamente foi possível observar que genótipos com a mesma genealogia (UPF 16 e UPF 17) ou com genealogias similares (UFRGS 15 e UFRGS 18) participaram dos mesmos grupos, na ausência de fungicida, comparado com aplicação de fungicida, em que se agruparam com outras constituições genéticas em grupos distintos; portanto, a aplicação de fungicida influenciou a expressão das constituições genéticas.

TABELA 4 - Agrupamento dos genótipos, utilizando-se a distância generalizada $\mathrm{D}^{2}$ de Mahalanobis e o método de otimização de Tocher.

\begin{tabular}{clll}
\hline Grupo & \multicolumn{1}{c}{ Com fungicida } & & \multicolumn{1}{c}{ Sem fungicida } \\
\cline { 1 - 2 } I & UPF 19, UPF 15, UFRGS 17, UFRGS 16, OR 2, & & UPF 16 e UPF 17 \\
& UPF 16 e UFRGS 14 & & \\
II & UFRGS 7, URS 20, URS 21 e UFRGS 19 & & UFRGS 15 e UFRGS 18 \\
III & UFRGS 15, UFRGS 18 e UPF 7 & & UPF 19, UFRGS 17, UFRGS 16, UPF 15, UPF 18 \\
& & UPF 18 & e UPF 7 \\
IV & OR 3 & UFRGS 7, UFRGS 19, OR 2 e URS 20 \\
V & OR & UFRGS 14 e OR 3 \\
VI & UPF 17 & IAC 7 \\
VII & IAC 7 & URS 21 \\
\hline
\end{tabular}

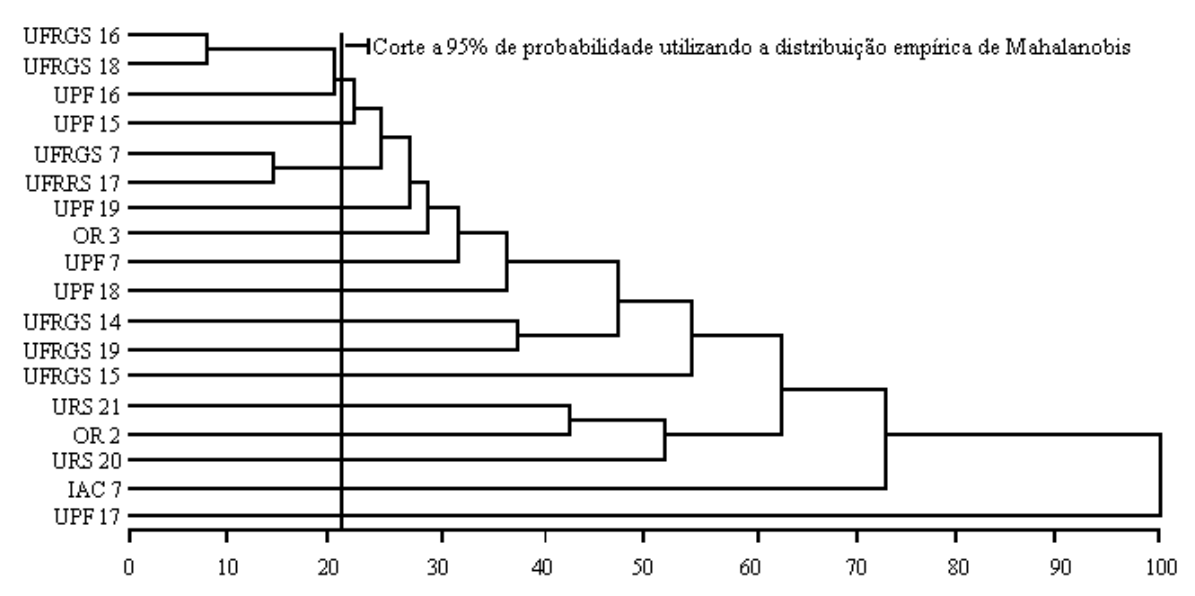

FIGURA 3 - Dendrograma representativo da dissimilaridade genética entre os genótipos, com aplicação de fungicida, obtida pela técnica do vizinho mais próximo, utilizando $\mathrm{D}^{2}$ como medida de dissimilaridade. 


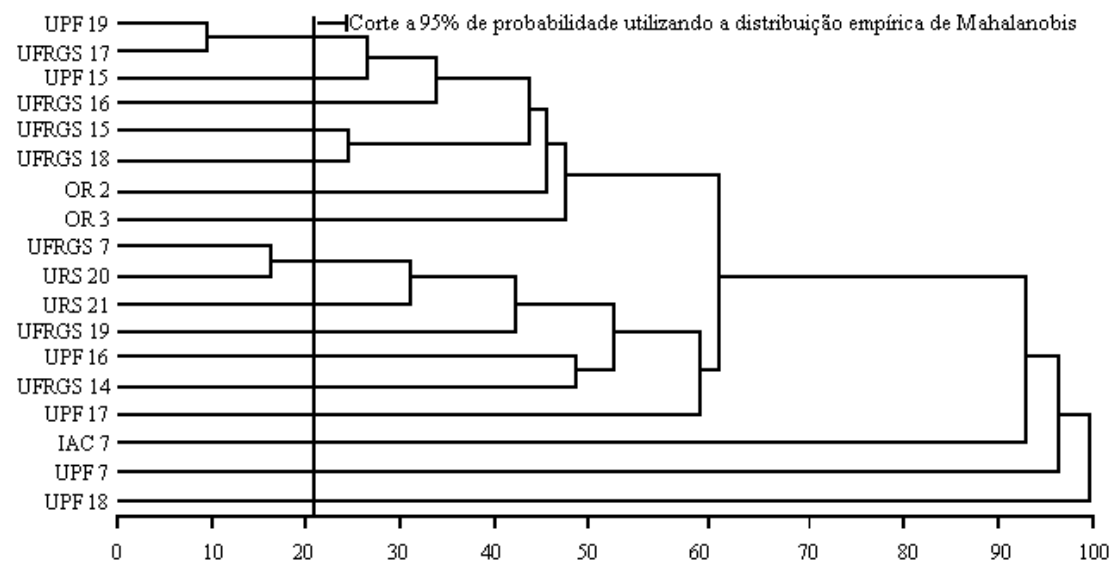

FIGURA 4 - Dendrograma representativo da dissimilaridade genética entre os genótipos, sem aplicação de fungicida, obtida pelo método hierárquico do vizinho mais próximo, utilizando $\mathrm{D}^{2}$ como medida de dissimilaridade.

Esse fato sugere que a seleção dos genitores mais divergentes, preferencialmente, deve ser realizada em ambientes naturais, ou seja, sem a aplicação de fungicida, em que genótipos com genealogias idênticas ou similares permaneceram nos mesmos grupos. A utilização do corte efetuado nos dendrogramas pela metodologia proposta por Mourão Junior (2001) sugere que para obter maior variabilidade nos cruzamentos os genótipos de um lado da linha devem ser cruzados com os do outro lado da mesma. Objetivando cruzamentos altamente divergentes, os genótipos UPF 19 e UFRGS 17 podem ser cruzados com UPF 18 (Figura 4), e com a aplicação de fungicida, os genótipos UFRGS 16 e UFGRS 18 podem ser cruzados com UPF 17 (Figura $3)$.

A identificação dos caracteres que menos contribuíram para a divergência genética observada entre os genótipos por intermédio dos maiores coeficientes, em valor absoluto, a eles associados nas últimas variáveis canônicas, pode ser realizada como mostra a Tabela 5. Esse procedimento, conforme Cruz \& Regazzi (1997), utiliza o princípio de que um caráter pode ser descartável se for mais importante para uma variável canônica, que não contribui ou que pouco contribui para a variação total. Entretanto, Morais et al. (1998) discutem a validade do descarte de uma variável que pode ser também relevante para as primeiras variáveis canônicas, apenas porque o coeficiente de ponderação a ela associada na transformação das variáveis originais é classificado entre os maiores nas últimas variáveis canônicas. Como é o caso dos caracteres estatura de planta (EP) e peso do hectolitro $(\mathrm{PH})$, com fungicida e peso do hectolitro $(\mathrm{PH})$ e dias da emergência à floração (DEF) na ausência do efeito do fungicida para o controle de moléstias, que são respectivamente na ordem as duas primeiras variáveis consideradas descartáveis em cada ambiente, (Tabela 5). Segundo Cruz (1990), caracteres considerados descartáveis que são altamente correlacionados com outros caracteres considerados não descartáveis (Tabela 6) são caracteres redundantes, ou seja, que podem ser representados por outros caracteres.

$\mathrm{Na}$ Tabela 7, está incluída a forma de identificação das contribuições relativas de cada caráter para a dissimilaridade genética observada. Pode ser verificado que em ambos os ambientes, com e sem o emprego de fungicida para o controle de moléstias da parte aérea, os caracteres de maior importância foram peso do hectolitro $(\mathrm{PH})$ e estatura de planta (EP), que contribuíram com $31,52 \%$ e $36,91 \%$ com fungicida e $31,75 \%$ e $25,48 \%$ sem fungicida, da dissimilaridade genética total. Pode ser observado que os caracteres não tiveram a mesma estimativa da contribuição relativa e nem a ordem de classificação para a contribuição da dissimilaridade genética nos dois ambientes. Esses resultados concordam com os obtidos por Coimbra (1999). 
TABELA 5 - Coeficientes de ponderação das variáveis originais padronizados para obtenção das variáveis canônicas (VC) e variâncias acumuladas (VA) explicadas pelas VC e indicação das variáveis descartáveis (VD).

\begin{tabular}{|c|c|c|c|c|c|c|c|c|c|c|c|c|}
\hline \multirow{2}{*}{ VC } & \multicolumn{6}{|c|}{ Com fungicida } & \multicolumn{6}{|c|}{ Sem fungicida } \\
\hline & RGD & PMG & PH & EP & DEF & $\overline{\text { VA }}$ & RGD & PMG & $\mathbf{P H}$ & EP & DEF & VA \\
\hline 1 & 0,0004 & $-0,394$ & $-0,162$ & 0,048 & 0,511 & 66,3 & 0,0006 & $-0,064$ & 0,335 & 0,167 & 0,111 & 44,4 \\
\hline 2 & 0,0002 & 0,092 & 0,135 & 0,135 & $-0,038$ & 82,1 & $-0,0003$ & 0,251 & $-0,253$ & 0,099 & 0,334 & 77,5 \\
\hline 3 & 0,0002 & 0,241 & 0,170 & $-0,713$ & 0,148 & 89,6 & $-0,0009$ & 0,501 & $-0,117$ & 0,039 & $-0,208$ & 94,5 \\
\hline 4 & 0,0016 & $-0,006$ & $-0,172$ & 0,032 & $-0,151$ & 95,4 & 0,0018 & 0,134 & $-0,045$ & $-0,102$ & 0,156 & 97,9 \\
\hline 5 & 0,0012 & $-0,146$ & 0,308 & $-0,446$ & 0,145 & 100 & $-0,0016$ & 0,126 & 0,230 & $-0,086$ & 0,160 & 100 \\
\hline VD & - & - & $2^{\mathrm{a}}$ & $1^{\mathrm{a}}$ & - & & - & - & $1^{\mathrm{a}}$ & - & $2^{\mathrm{a}}$ & \\
\hline
\end{tabular}

TABELA 6 - Correlações genotípicas entre os caracteres rendimento de grãos desaristados (RGD), peso de mil grãos (PMG), peso do hectolitro $(\mathrm{PH})$, estatura de planta $(\mathrm{EP})$ e dias da emergência à floração (DEF) dos genótipos estudados.

\begin{tabular}{|c|c|c|c|c|c|c|c|c|}
\hline \multirow{2}{*}{ Caráter } & \multicolumn{4}{|c|}{ Com fungicida } & \multicolumn{4}{|c|}{ Sem fungicida } \\
\hline & PMG & PH & $\mathbf{E P}$ & DEF & PMG & PH & EP & DEF \\
\hline RGD & 0,30 & $-0,33$ & 0,08 & 0,28 & 0,44 & $0,90^{*}$ & 0,45 & $-0,30$ \\
\hline PMG & & 0,23 & 0,13 & $-0,07$ & & 0,41 & $0,48^{*}$ & $-0,25$ \\
\hline PH & & & 0,15 & $-0,72 *$ & & & $0,48^{*}$ & $-0,41$ \\
\hline EP & & & & 0,37 & & & & 0,41 \\
\hline
\end{tabular}

* Significativas a $95 \%$ de probabilidade pelo teste $t$.

TABELA 7 - Contribuição relativa dos caracteres $\left(\mathrm{S}_{._{\mathrm{v}}}\right.$ ) para a dissimilaridade genética, rendimento de grãos desaristados (RGD), peso de mil grãos (PMG), peso do hectolitro (PH), estatura de planta (EP) e dias da emergência à floração (DEF).

\begin{tabular}{cccccc}
\hline \multirow{2}{*}{ Caráter } & \multicolumn{2}{c}{ Com fungicida } & & \multicolumn{2}{c}{ Sem fungicida } \\
\cline { 2 - 3 } \cline { 5 - 6 } & $\mathbf{S . v}_{\mathbf{v}}$, & $\boldsymbol{\%}$ & & $\mathbf{S . v}_{\mathbf{v}}$, & \% \\
\hline RGD & 257,20 & 12,55 & & 480,13 & 6,61 \\
PMG & 338,22 & 16,50 & & 1003,99 & 13,91 \\
PH & 646,01 & 31,52 & & 2307,92 & 31,75 \\
EP & 756,52 & 36,91 & & 1851,85 & 25,48 \\
DEF & 51,73 & 2,52 & & 1624,09 & 22,35 \\
\hline
\end{tabular}




\section{CONCLUSÕES}

Há significativa dissimilaridade genética entre os genótipos testados de aveia, e os caracteres que mais contribuíram para a dissimilaridade genética foram peso do hectolitro e estatura de planta. Considerável variabilidade genética poderá ser obtida em cruzamentos artificiais entre esses genótipos.

\section{REFERÊNCIAS BIBLIOGRÁFICAS}

CASLER, M. D. Patterns of variation in a collection of perennial ryegrass accessions. Crop Science, Madison, v. 35, n. 5, p. 1169-1177, 1995.

COIMBRA, J. L. M.; CARVALHO, F. I. F.; HEMP, S.; OLIVEIRA, A. C.; SILVA, S. A. Divergência genética em feijão preto. Ciência Rural, Santa Maria, v. 29, p. 427-431, 1999.

CRUZ, C. D. Aplicação de algumas técnicas multivariadas no melhoramento de plantas. 1990. 188 p. Tese (Doutorado) - Escola Superior de Agricultura "Luiz de Queirós", Piracicaba.

CRUZ, C. D. Programa genes: aplicativo computacional em genética e estatística. Viçosa: UFV, 2001. $648 \mathrm{p}$.

CRUZ, C. D.; REGAZZI, A. J. Modelos biométricos aplicados ao melhoramento genético. 2. ed. Viçosa: UFV, 1997. $390 \mathrm{p}$.

GAUR, P. C.; GRUPTA, P. K.; KISHORI, H. Studies on genetic divergence in potato. Euphytica, Wageningen, v. 27, p. 316-368, 1978.
MACHADO, C. F. Procedimentos para a escolha de genitores de feijão. 1999. 118 p. Dissertação (Mestrado) - Universidade Federal de Lavras, Lavras.

MORAIS, O. P.; SILVA, J. C.; CRUZ, C. D; REGAZZI, A. D.; NEVES, P. C. F. Divergência genética entre os genitores da população de arroz irrigado CNA-IRAT 4. Pesquisa Agropecuária Brasileira, Brasília, v. 28, p. 150-158, 1998.

MOURÃO JUNIOR, M. Avaliação de um critério probabilístico em análise multivariada de agrupamento (Cluster analysis), por meio de simulação Monte Carlo. 2001. 78 p. Dissertação (Mestrado em Estatística e Experimentação Agropecuária) - Universidade Federal de Lavras, Lavras.

RAO, R. C. Advanced statistical methods in biometric research. New York: John Wiley, 1952. $390 \mathrm{p}$.

SANTOS, C. F.; MENEZES, E. A.; ARAÚJO, F. P. Divergência genética em genótipos de feijão-de-corda avaliados em dois ambientes. Ceres, Viçosa, v. 44, n. 251, p. 35-42, 1997.

SCOTT, A. J.; KNOTT, M. A. Cluster analysis methods for grouping means in the analysis of variance. Biometrics, Washington, v. 30, p. 507-512, 1974.

SINGH, D. The relative importance of characters affecting genetic divergence. The Indian Journal of Genetics \& Plant Breeding, New Delhi, v. 41 p. 237$245,1981$. 